\title{
Reflecting on Australia's five principles for pandemic response in primary care through the lens of early international experiences of COVID-19
}

Jane Desborough, Sally Hall Dykgraaf, Stephanie Davis, Michael Kidd

FIVE PRINCIPLES have underpinned Australia's primary care response to COVID-19: 1) protection of vulnerable people, 2) provision of treatment and support services to affected people, 3) continuity of regular healthcare services for the whole population, 4) protection and support of primary care workers and services and 5) provision of mental health services to the community and the primary care workforce. ${ }^{1,2}$ These were rapidly developed to inform policy at the beginning of the pandemic in collaboration with representatives from the primary healthcare sector, general practice and more than 30 peak national organisations. ${ }^{1}$

In scoping the emerging literature on COVID-19 during 2020 and considering its policy relevance, we identified six emerging challenges that highlight the importance of the five principles. These challenges were: 1 ) improving collaboration between primary care and public health, 2) including primary care-tailored guidance in pandemic preparedness plans, 3 ) ensuring provision of regular primary healthcare, 4) using alternative consultation modalities to provide healthcare, 5) improving approaches to sourcing, stockpiling and distributing personal protective equipment (PPE) and 6) supporting the mental health of the primary care workforce and patients.

We examine the relevance of the five principles to reported experiences of COVID-19 through the lens of these six key challenges. We show the interconnectedness of the five principles and their applicability to each of the challenges in Table 1.

\section{Improving collaboration between primary care and public health While primary care and public gain sufficient understanding of the issues that will influence primary care response strategies for health sector preparedness.} health are complementary primary healthcare initiatives, epidemics are largely considered to be public health emergencies, with little emphasis on the critical role of primary care in providing first-contact care. Challenges to collaboration between primary care and public health relate to differing functions and responsibilities, and limited mutual understanding. ${ }^{3,4}$ Collaboration is an essential foundation for effective information sharing; primary care clinicians and organisations have insights to share regarding the communities they serve and their vulnerabilities, and specific primary care workforce and services requirements. ${ }^{5}$

While there is some current evidence of effective health sector collaboration, ${ }^{6,7}$ in many countries primary care specialists are notably absent from COVID-19 taskforces; politicians, public health specialists and epidemiologists predominate while others, including mental and social health experts, are omitted. ${ }^{8}$ The Australian Health Protection Principal Committee, the peak medical advisory committee to the Australian Government, included primary healthcare experts in daily meetings throughout the early months of the pandemic. ${ }^{9}$ A primary care voice at decision-making tables enables activation of the five principles from the beginning identifying vulnerable populations, health workforce needs and appropriate response planning. Without this, it is impossible to

\section{Including primary} care-tailored guidance in pandemic preparedness plans

Guidelines tailored to each component of the sector, including primary care, are essential to inform coherent participation of frontline clinicians in the response. ${ }^{10-13}$ Specific tailoring may also be needed when epidemiological context varies at different times and to different degrees across geographic boundaries. ${ }^{14}$ Appropriately tailored guidance supports enaction of the principles relating to treatment and support of affected people, and continuity of regular healthcare provision. It also shapes workforce participation to protect patients and healthcare workers from disease transmission.

While some countries have developed primary care consensus standards for COVID-19, ${ }^{15,16}$ internationally, primary care clinicians have reported enormous clinical and emotional burden in responding, with many feeling ill-informed regarding how to fulfil their roles. ${ }^{17,18}$ While they have been creative in response - developing 
local health professional hubs, sharing workforce, establishing dedicated clinics, ${ }^{17}$ introducing or expanding digital consultation methods and triaging COVID-19 from non-COVID-19 care $^{18}$ their call for clear and consistent guidance is resounding. ${ }^{17-20}$

\section{Ensuring provision of regular primary healthcare}

COVID-19 has exacerbated many existing health disparities. ${ }^{21}$ The principle of ensuring continuity of regular healthcare services for the whole population protects those who are most vulnerable, including people with new and existing mental health problems. Internationally, disruptions to all essential services have been reported, especially in lowand middle-income countries, where reproductive, maternal, newborn, child and adolescent health services have been substantially affected, increasing mortality risk among these vulnerable populations. ${ }^{22}$ Some high-income countries have prioritised primary care provision of mental health and social care, ${ }^{23}$ reporting reductions in adult vaccinations, routine health checks and chronic care. ${ }^{23,24}$

\section{Using alternative consultation modalities to provide healthcare \\ Widespread uptake of telehealth} consultations has played a substantial role in facilitating management of COVID-19 and non-COVID-19 care $^{25,26}$ While simultaneously protecting vulnerable patients and clinicians, ${ }^{7,27}$ unprecedented transition to telehealth internationally has enabled treatment and advice to people with COVID-19, preserved the provision of regular healthcare services and maintained workforce capacity through minimising transmission risks, ${ }^{7}$ reflective of all five principles.

However, telehealth may not work for some patients with complex needs and is not always an appropriate substitute for in-person care..$^{28,29}$ Disparities in internet access, digital readiness and infrastructure suitability may accentuate inequity, ${ }^{23,30}$ especially for the elderly, ${ }^{31}$ people with disability ${ }^{32,33}$ and those living in rural and remote areas. ${ }^{34}$ Identifying and responding to these vulnerabilities needs to be prioritised to fully realise the first principle.

\section{Improving approaches to sourcing, stockpiling and distributing personal protective equipment}

Adequate and appropriate PPE is a critical antecedent for the protection and support of primary care workers and services, safe treatment of individuals with suspected or diagnosed COVID-19 and, in turn, the continued provision of regular healthcare services.

During COVID-19, clinicians have reported being ill-equipped to protect themselves and their patients. ${ }^{18,24}$ Protection and support of primary care workers, including access to appropriate and sufficient PPE, is ultimately linked to workforce mental health and wellbeing. ${ }^{35,36}$ The impact on the health workforce has been significant, including elevated anxiety levels; the Australian Government has prioritised implementation of the fourth principle, the protection and support of primary care workers and services, to address this. ${ }^{7}$

\section{Supporting the mental health of the primary care workforce and patients}

High levels of stress among primary care workers and increased suicidality among patients have been reported; ${ }^{23}$ many are afraid of contracting COVID-19 and of passing it on to others, including family members. ${ }^{23,37}$ Some primary care staff have lost their jobs or been forced to reduce hours due to illness or lack of practice income as a result of COVID-19. ${ }^{23,24}$ The principle of providing mental health services for the community and primary care clinicians is fundamental to developing community resilience ${ }^{38}$ and preserving workforce capacity to provide treatment and support for both people with COVID-19 and regular healthcare services. Some require the development of new skillsets to achieve this. Managing work-related exposure risk is a critical work health and safety issue, and a fundamental pillar of mental health and wellbeing for the primary care workforce.

Connecting COVID-19 experiences with underpinning principles The five principles underpinning Australia's primary care response to COVID-19 respond directly to the early COVID-19 experiences described. In fact, some directly mirror key challenges, such as the continuity of regular primary care, the protection of primary care workers and services, and support for the mental health of the primary care workforce and the community. The use of a matrix demonstrates overlap between the principles, which we feel provides a protective effect, ensuring that the whole population is considered and cared for through provision of treatment and support for patients with COVID-19, continuity of regular healthcare and provision of mental health support. We believe the five principles capture the key policy requirements to inform a well-rounded primary care response.

First published online 5 February 2021.

\section{Authors}

Jane Desborough RN, RM, MPH, PhD, Action Research, COVID-19 Primary Care Response Group (seconded), Primary Care Division, Australian Government Department of Health, ACT; Senior Research Fellow, Research School of Population Health, College of Health and Medicine, Australian National University, ACT; Program Leader, Health Experience Team, Our Health in Our Hands $(\mathrm{OHIOH})$, Australian National University, ACT

Sally Hall Dykgraaf RN, Grad Cert ClinMan, PhD Scholar, Action Research, COVID-19 Primary Care Response Group (seconded), Primary Care Division, Australian Government Department of Health, ACT; Research Manager, Rural Clinical School, Australian National University, ACT

Stephanie Davis MBBS, MAppEpi, Medical Advisor, COVID-19 Primary Care Response Group, Australian Government Department of Health, ACT; Medical Advisor, National Centre for Epidemiology and Population Health, Australian National University, Canberra, ACT

Michael Kidd AM MBBS (Hons), MD, DCCH, DipRACOG, MCFP, FAHMS, Principal Medical Advisor and Deputy Chief Medical Officer, Australian Government Department of Health, ACT; Professor of Primary Care Reform, Australian National University, ACT; Adjunct Professor, Department of Family and Community Medicine, University of Toronto, Canada; Emeritus Director, World Health Organization

Collaborating Centre on Family Medicine and Primary Care, GVA; Professorial Fellow, Murdoch Children's Research Institute, The Royal Children's Hospital 
Melbourne, Vic; Honorary Professor of Global Primary Care, Southgate Institute for Health, Society and Equity, Flinders University, SA

Competing interests: None.

Providence and peer reviewer: Not commissioned, externally peer reviewed.

Citation: Desborough J, Hall Dykgraaf S, Davis S, Kidd M. Reflecting on Australia's five principles for pandemic response in primary care through the lens of early international experiences of COVID-19. Aust J Gen Pract 2020;50 Suppl 46. doi: 10.31128/AJGPCOVID-46.

\section{Acknowledgement}

The authors acknowledge the work of members of the Australian Government Department of Health COVID-19 Primary Care Response Group, which has informed this article.

Correspondence to:

jane.desborough@anu.edu.au

\section{References}

1. Kidd M. Principles for primary care pandemic preparedness: Lessons from the Australian COVID-19 primary care response. Br J Gen Pract 2020;70(696):316-17. doi: 10.3399/ bjgp20X710765.

2. Kidd M. Australia's primary care COVID-19 response. Aust J Gen Pract 2020;49 Suppl 2. doi: 10.31128/AJGP-COVID-02.

3. Phillips $\mathrm{C}$. Resistance and accommodation in pandemic preparation and response in general practice and the ethnographic eye: Culture, change and the organisation. Canberra, ACT: ANU, 2016.

4. Masotti $\mathrm{P}$, Green ME, Birtwhistle R, et al. pH1N1 A comparative analysis of public health responses in Ontario to the influenza outbreak, public health and primary care: Lessons learned and policy suggestions. BMC Public Health 2013;13:687. doi: 10.1186/1471-2458-13-687.

5. Nazareth J, Minhas JS, Jenkins DR, et al. Early lessons from a second COVID-19 lockdown in Leicester, UK. Lancet 2020;396(10245):e4-e5. doi: 10.1016/S0140-6736(20)31490-2.

6. Bhattacharyya O, Agarwal P. Adapting primary care to respond to COVID-19. 9 Apr 2020. The office journal of the College of Family Physicians of Canada. Available at www.cfp.ca/ news/2020/04/09/04-09-1 [Accessed 22 Jan 2020].

7. Desborough J, Hall Dykgraaf S, de Toca L, et al Australia's national COVID-19 primary care response. Med J Aust 2020;213(3):104-06e1. doi: 10.5694/mja2.50693.

8. Rajan D, Koch K, Rohrer K, et al. Governance of the Covid-19 response: A call for more inclusive and transparent decision-making. BMJ Glob Health 2020;5(5):e002655. doi: 10.1136/bmjgh-2020002655.

9. Department of Health. Australian Health Protection Principal Committee (AHPPC) Canberra, ACT: DoH, 2020. Available at www. health.gov.au/committees-and-groups/ australian-health-protection-principal-committeeahppc\#member [Accessed 21 January 2021].

10. Kunin M, Engelhard D, Thomas S, Ashworth M, Piterman L. Influenza pandemic 2009/A/ H1N1 management policies in primary care: A comparative analysis of three countries. Aust Health Rev 2013;37(3):291-99. doi: 10.1071/ $\mathrm{AH} 12022$
11. SARS Expert Committee. SARS in Hong Kong: From experience to action. Hong Kong, CN: SARS Expert Committee, 2003.

12. The SARS Commisssion. The SARS commission report. Toronto, ON: The SARS Commission, 2006. Available at ww.archives.gov.on.ca/en/e_records/ sars/report/v1.html [Accessed 21 January 2021].

13. Wong SY, Kung K, Wong MC, et al. Primary care physicians' response to pandemic influenza in Hong Kong: A mixed quantitative and qualitative study. Int J Infect Dis 2012;16(9):e687-91. doi: 10.1016/j.ijid.2012.03.015.

14. Sweet M. Pandemic lessons from Australia. BMJ 2009;339:b3317. doi: 10.1136/bmj.b3317.

15. Kumar R, Boobna V, Kubendra M, Kaimal R, Velavan J, Venkapalli S. Ensuring continuity of care by small family practices and clinics in the primary care setting during COVID 19 pandemic 2020 - A position paper by the Academy of Family Physicians of India. J Family Med Prim Care 2020;9(4):1798-800. doi: 10.4103/jfmpc. jfmpc_620_20.

16. Mendis K, Wickramasinghe A, Senaratne $L$, et al. COVID-19 Interim guidelines for Sri Lankan primary care physicians. Version 3.1. Gujarat, IN: SAARC, 2020.

17. Thornton J. Covid-19: How coronavirus will change the face of general practice forever BMJ 2020;368:m1279. doi: 10.1136/bmj.m1279.

18. Rawaf S, Allen LN, Stigler FL, et al. Lessons on the COVID-19 pandemic, for and by primary care professionals worldwide. Eur J Gen Pract 2020;26(1):129-33. doi: 10.1080/13814788.2020.1820479.

19. Sayburn A. Are UK doctors getting sufficient protective equipment against covid-19? BM 2020;369:m1297. doi: 10.1136/bmj.m1297.

20. Douglas K, Barnes K, Hall S, O'Brien K. COVID-19 General Practice Clinicians: 5 Minute Survey: Series 6. Canberra, ACT: ANU, 2020. Available at https:/medicalschool.anu.edu.au/research/ projects/covid-19-general-practice-clinicians-5minute-survey [Accessed 4 February 2021].

21. Dorn AV, Cooney RE, Sabin ML. COVID-19 exacerbating inequalities in the US. Lancet 2020;395(10232):1243-44. doi: 10.1016/S01406736(20)30893-X

22. World Health Organization. Pulse survey on continuity of essential health services during the COVID-19 pandemic. Interim report: 27 August 2020. Geneva, CH: WHO, 2020.

23. Etz R. Quick COVID-19 primary care weekly survey, week 10 + green center/PCC press release. Richmond, VA: The Larry A. Green Center, 2020.

24. Halcomb E, Mclnnes S, Williams A, et al. The experiences of primary healthcare nurses during the COVID-19 pandemic in Australia. J Nurs Scholarsh 2020;52(5):553-63. doi: 10.1111/ jnu.12589.

25. Webster P. Virtual health care in the era of COVID19. Lancet 2020;395(10231):1180-81. doi: 10.1016/ S0140-6736(20)30818-7.

26. Browne R. Demand for telemedicine has exploded in the UK as doctors adapt to the coronavirus crisis. CNBC. 15 Apr 2020. Available at www.cnbc.com/2020/04/09/ telemedecine-demand-explodes-in-uk-as-gpsadapt-to-coronavirus-crisis.html [Accessed 21 January 2021].

27. Moazzami B, Razavi-Khorasani $N$ Dooghaie Moghadam A, Farokhi E, Rezaei N COVID-19 and telemedicine: Immediate action required for maintaining healthcare providers wellbeing. J Clin Virol 2020;126:104345. doi: 10.1016/j. jcv.2020.104345.
28. Consumers Health Forum of Australia. What Australia's health panel said about telehealth March/April 2020. Deakin, ACT: CHF, 2020. Available at https://chf.org.au/ahptelehealth [Accessed 21 January 2021].

29. Douglas K, Barnes K, Hall S, O'Brien K. COVID-19 General Practice Clinicians: 5 Minute Survey: Series 11. Canberra, ACT: ANU, 2020. Available at https://medicalschool.anu.edu.au/research/ projects/covid-19-general-practice-clinicians-5minute-survey [Accessed 4 February 2021].

30. Anonymous. A month in primary care with coronavirus: Sudden death, end of life discussions, lockdown and inequalities. A better NHS. 16 Apr 2020. Available at https://abetternhs. net/2020/04/16/a-month-in-primary-carewith-coronavirus-sudden-death-end-of-lifediscussions-lockdown-and-inequalities [Accessed 22 January 2020].

31. Wicklund E. Surveys suggest seniors aren't using telehealth during COVID-19 crisis. Xtelligent Healthcare Media. 27 May 2020. Available at https://mhealthintelligence.com/news/ surveys-suggest-seniors-arent-using-telehealthduring-covid-19-crisis [Accessed 22 January 2020].

32. Nguyen A, Cartmill J, White S. Amid the rush to telehealth, let's ensure we address these cautions and questions. Croakey. 18 May 2020. Available at www.croakey.org/ amid-the-rush-to-telehealth-lets-ensure-weaddress-these-cautions-and-questions [Accessed 22 January 2020].

33. Thomas J, Barraket J, Wilson CK, Rennie E, Ewing S, MacDonaldT. Measuring Australia's digital divide: The Australian digital inclusion index 2019. Melbourne, Vic: RMIT University and Swinburne University of Technology, 2019.

34. Thomas J, Wilson CK, Park S. Australia's digital divide is not going away. The Conversation. $29 \mathrm{Mar}$ 2018. Available at https://theconversation.com/ australias-digital-divide-is-not-going-away-91834 [Accessed 22 January 2020].

35. Wong WC, Lee A, Tsang KK, Wong SY. How did general practitioners protect themselves, their family, and staff during the SARS epidemic in Hong Kong? J Epidemiol Community Health 2004;58(3):180-85. doi: 10.1136/ jech.2003.015594.

36. Ontario College of Family Physicians. The mushroom syndrome: SARS and family medicine. Toronto, ON: OCFP, 2003.

37. Lewin E. Risk of infecting others with COVID-19 key concern for healthcare workers. newsGP. $3 \mathrm{Apr}$ 2020. Available at www1.racgp.org.au/newsgp/ clinical/risk-of-infecting-others-with-covid-19-akey-conce [Accessed 22 January 2020].

38. Desborough J, Blashki G, Hall S, et al. Community activation, policy and COVID-19. In: World Federation For Mental Health. World mental health day 2020. Mental health for all: Greater investment-greater access. San Antonio, TX: WFMH, 2020. 
Table 1. Matrix of the five principles in relation to early international experiences of COVID-19

\begin{tabular}{|c|c|c|c|c|c|c|}
\hline & \multicolumn{6}{|c|}{ Principle } \\
\hline & & $\begin{array}{l}\text { 1. Protection of vulnerable } \\
\text { people }\end{array}$ & $\begin{array}{l}\text { 2. Provision of treatment } \\
\text { and support services to } \\
\text { affected people }\end{array}$ & $\begin{array}{l}\text { 3. Continuity of regular } \\
\text { healthcare services for } \\
\text { the whole population }\end{array}$ & $\begin{array}{l}\text { 4. Protection and support } \\
\text { of primary care workers } \\
\text { and services }\end{array}$ & $\begin{array}{l}\text { 5. Provision of mental } \\
\text { health services to the } \\
\text { community and the } \\
\text { primary care workforce }\end{array}$ \\
\hline & $\begin{array}{l}\text { 1. Improving collaboration } \\
\text { between primary care } \\
\text { and public health }\end{array}$ & $\begin{array}{l}\text { Local, regional and national } \\
\text { identification of vulnerable } \\
\text { populations }\end{array}$ & \multicolumn{2}{|c|}{$\begin{array}{l}\text { Understanding of issues that influence implementation } \\
\text { of primary care response }\end{array}$} & $\begin{array}{l}\text { Identification of primary } \\
\text { care workforce needs }\end{array}$ & $\begin{array}{l}\text { Clarification of health and } \\
\text { social care networks and } \\
\text { services }\end{array}$ \\
\hline$\stackrel{0}{\circ}$ & $\begin{array}{l}\text { 2. Including primary } \\
\text { care-tailored } \\
\text { guidance in pandemic } \\
\text { preparedness plans }\end{array}$ & $\begin{array}{l}\text { Primary care-tailored } \\
\text { guidelines for identified } \\
\text { vulnerable populations }\end{array}$ & \multicolumn{2}{|c|}{$\begin{array}{l}\text { Coherent participation of primary care clinicians } \\
\text { in pandemic response }\end{array}$} & $\begin{array}{l}\text { Primary care role } \\
\text { clarification }\end{array}$ & $\begin{array}{l}\text { Role clarification and } \\
\text { guidance reducing stress }\end{array}$ \\
\hline \multirow[t]{4}{*}{ 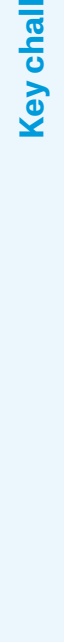 } & $\begin{array}{l}\text { 3. Ensuring provision } \\
\text { of regular primary } \\
\text { healthcare }\end{array}$ & $\begin{array}{l}\text { Access to care, including } \\
\text { face-to-face, as required }\end{array}$ & $\begin{array}{l}\text { Clarification of separate } \\
\text { pathways of care for } \\
\text { affected people }\end{array}$ & $\begin{array}{l}\text { Understanding differences } \\
\text { between low-, middle- and } \\
\text { high-income countries }\end{array}$ & $\begin{array}{l}\text { Protection of primary care } \\
\text { workers and services }\end{array}$ & $\begin{array}{l}\text { Ensuring access to } \\
\text { ongoing mental healthcare }\end{array}$ \\
\hline & $\begin{array}{l}\text { 4. Using alternative } \\
\text { consultation modalities } \\
\text { to provide healthcare }\end{array}$ & $\begin{array}{l}\text { Protection of vulnerable } \\
\text { patients and clinicians; } \\
\text { identification of disparities } \\
\text { in access to telehealth }\end{array}$ & $\begin{array}{l}\text { Provision of treatment and } \\
\text { advice to patients with } \\
\text { COVID-19 }\end{array}$ & $\begin{array}{l}\text { Provision of regular } \\
\text { healthcare services }\end{array}$ & $\begin{array}{l}\text { Minimisation of } \\
\text { transmission risk }\end{array}$ & $\begin{array}{l}\text { Access to new and ongoing } \\
\text { mental healthcare }\end{array}$ \\
\hline & $\begin{array}{l}\text { 5. Improving approaches } \\
\text { to sourcing, stockpiling } \\
\text { and distributing personal } \\
\text { protective equipment }\end{array}$ & \multicolumn{3}{|c|}{ Minimisation of transmission risk } & \multicolumn{2}{|c|}{$\begin{array}{l}\text { Distribution of personal protective equipment to primary } \\
\text { care workers and services }\end{array}$} \\
\hline & $\begin{array}{l}\text { 6. Supporting the mental } \\
\text { health of the primary care } \\
\text { workforce and patients }\end{array}$ & $\begin{array}{l}\text { Identification of vulnerable } \\
\text { clinicians and patients }\end{array}$ & \multicolumn{2}{|c|}{$\begin{array}{l}\text { Clarified pathways of care reduce unwarranted stress for } \\
\text { clinicians and patients }\end{array}$} & \multicolumn{2}{|c|}{$\begin{array}{l}\text { Access to mental health support both virtually and face- } \\
\text { to-face as required }\end{array}$} \\
\hline
\end{tabular}

